\title{
Herb-Partitioned Moxibustion Regulates the TLR2/NF- $\kappa$ B Signaling Pathway in a Rat Model of Ulcerative Colitis
}

\author{
Xiaomei Wang, ${ }^{1}$ Yanan Liu, ${ }^{2}$ Hongsheng Dong, ${ }^{1}$ Luyi Wu, ${ }^{2}$ Xiaoming Feng, \\ Zhigang Zhou, ${ }^{2}$ Chen Zhao, ${ }^{1}$ Huirong Liu, ${ }^{2}$ and Huangan $\mathrm{Wu}^{2}$ \\ ${ }^{1}$ Yueyang Hospital of Integrated Traditional Chinese and Western Medicine, Shanghai University of Traditional Chinese Medicine, \\ Shanghai 200437, China \\ ${ }^{2}$ Key Laboratory of Acupuncture-Moxibustion and Immunological Effects, Shanghai University of Traditional Chinese Medicine, \\ Shanghai 200030, China
}

Correspondence should be addressed to Huirong Liu; 1hr_tcm@139.com and Huangan Wu; wuhuangan@126.com

Received 31 December 2014; Accepted 2 June 2015

Academic Editor: Tetsuya Kondo

Copyright (C) 2015 Xiaomei Wang et al. This is an open access article distributed under the Creative Commons Attribution License, which permits unrestricted use, distribution, and reproduction in any medium, provided the original work is properly cited.

\begin{abstract}
The TLR2/NF- $\kappa$ B signaling pathway plays an important role in the pathomechanism of ulcerative colitis (UC); acupuncture and moxibustion can improve the damage in colonic tissues of UC, but the regulatory mechanism remains unknown. This study observed the effect of moxibustion on the TLR2/NF- $\kappa$ B signaling pathway at the Tianshu (ST25) and Qihai (CV6) acupuncture points in the UC rat. The result shows that TLR2, IRAK1, and IKK-b mRNA and protein levels in the colonic mucosa were significantly higher in the UC rats than in the control rats. Herb-partitioned moxibustion reduced the expression of TLR2, IRAK1, and IKK-b mRNA and proteins in the UC rats. Similarly, the expression of NF- $\kappa$ B was significantly increased and IFN- $\beta$ and IL-10 were significantly decreased in the colonic mucosa of UC rats, but herb-partitioned moxibustion reduced the expression of IFN- $\beta$ and upregulating the expression of IFN- $\beta$ and IL-10 significantly. It indicates that herb-partitioned moxibustion can inhibit the expression of multiple signaling molecules of the TLR2 pathway effectively, and it may modulate the excessive local immune response by inhibiting TLR2 signaling, thereby promoting the repair of damaged colonic mucosa.
\end{abstract}

\section{Introduction}

Ulcerative colitis (UC), also known as nonspecific ulcerative colitis, is an inflammatory bowel disease (IBD) of unknown etiology. The incidence of IBD in China has shown a clear upward trend in recent years [1]. Although its pathogenesis is still largely unknown, progress in the study of the tolllike receptors (TLRs) and nuclear factor $-\kappa \mathrm{B}(\mathrm{NF}-\kappa \mathrm{B})$ has improved understanding of the pathogenic process of UC. Under normal physiological conditions, intestinal epithelial cells can tolerate the commensal bacteria in the gut and maintain homeostasis. Studies have demonstrated that "tolerance" and "nontolerance" of the intestinal mucosa towards intestinal bacteria are dependent on TLR-mediated signaling pathways [2]. TLR pathways also play important roles in maintaining tissue integrity and repairing damaged tissues [2]. TLRs play an immunoregulatory role in the colonic mucosa, since they activate downstream signaling pathways upon recognition of pathogen-associated molecular patterns (PAMPs) on pathogenic microbes [3-7]. TLRs are pattern recognition receptors that recognize common antigens on pathogenic microorganisms and they play key roles in the innate immune response [8]. Growing knowledge of the TLR/NF- $\kappa \mathrm{B}$ pathway provides a new opportunity in the research of UC pathogenesis. Inhibiting key molecules of this pathway to block excessive inflammation may be a new direction in the treatment of UC [9].

Many clinical and experimental studies have clearly demonstrated that acupuncture has a protective effect on the intestinal mucosa $[10,11]$. Long-term clinical and experimental studies have shown that herb-partitioned moxibustion is effective in the treatment of UC. It has been reported that TLR2 mRNA and protein are either not expressed or expressed at very low levels in the normal colonic mucosa of healthy human subjects but are upregulated in the colonic 
mucosa of patients with UC [12, 13]. Furthermore, the expression of TLR2 increases with the severity of the disease, as indicated by clinical and endoscopic examinations [12, 13]. In addition, there is more NF- $\kappa \mathrm{B}$ DNA binding activity in the nuclei of cells of the colonic mucosa of patients with UC than in those of other individuals $[14,15]$. This suggests that activation of the TLR/NF- $\kappa \mathrm{B}$ signaling pathways is closely associated with the development of UC. Based on previous studies, the activity of the TLR2/NF- $\kappa$ B pathway was here analyzed in UC rat colons to determine the therapeutic mechanisms of herb-partitioned moxibustion in UC. Upstream molecules TLR2, IRAK1, IKK- $\beta$, and NF- $\kappa$ B and downstream molecules IFN- $\beta$ and IL-10 served as markers.

\section{Materials and Methods}

2.1. Animals. Forty male Sprague-Dawley rats (specificpathogen-free), weighing $120 \pm 20 \mathrm{~g}$, were purchased from the Experimental Animal Center of the Fudan University School of Medicine. The animals were housed for seven days to allow them to adapt to the new environment before experimentation, and all animals were in good health when experimentation began.

2.2. Generation of the Ulcerative Colitis (UC) Model and Intervention. The $40 \mathrm{SD}$ rats were randomly divided into control, UC, UC with herb-partitioned moxibustion treatment, and UC with salicylazosulfapyridine (SASP) treatment groups. Except for rats in the control group, UC was induced in all rats using an immunological method combined with local irritation [16]. Adjuvant mixture (containing protein antigens released from UC colon patients) was injected into the front footpad, hind footpad, dorsa, inguinal, and abdominal cavities on days $0,10,17,24$, and 31 , respectively. On day 38 , rats were administered $3 \mathrm{~mL}$ of $3 \%$ formalin and a $2 \mathrm{~mL}$ enema of antigen fluid.

Rats in the control and UC groups did not receive any intervention, but they were sham-handled in the same way as rats in the intervention groups. Intervention was initiated immediately after UC generation. For herb-partitioned moxibustion, premade medicinal cakes (diameter $0.5 \mathrm{~cm}$, height $0.3 \mathrm{~cm}$ ) were placed on the Tianshu (ST25) and Qihai (CV6) acupuncture points [17], and moxa cones (Nanyang Hanye Moxa Plant, Henan, China) about $90 \mathrm{mg}$ in size were placed on the medicinal cakes. The moxa cones were ignited and allowed to burn out. Two cones were used for each acupuncture point once daily for a total of 14 times. For SASP treatment, salicylazosulfapyridine (SASP) (Lot\# 201007C30, Sunve Pharmaceutical Ltd., Shanghai, China) solution was administered by gavage. The dose was determined with the ratio of an adult human (70 kg body weight) per rat (200 g body weight) at 1:0.018 (Pharmacological Experimental Methodology). The SASP solution was administered twice daily, $3 \mathrm{~mL}$ each time, for a total of 14 days.

2.3. Tissue Collection. At the end of the intervention, animals were killed by cervical dislocation and their abdomens were opened. The colon was quickly removed (about $8 \mathrm{~cm}$ from the anus toward the proximal end) and dissected free of the surrounding connective tissues and fat. It was then cut open lengthwise, washed in saline, and laid flat in a dish mucosa side up, and the gross morphology of the mucosa was examined by eye. The colon was then divided in half. One piece was fixed in $10 \%$ neutral-buffered formalin, paraffin-embedded, and cut into sections. The other piece was immediately frozen in liquid nitrogen and stored at $-80^{\circ} \mathrm{C}$ for RNA preparation and qRT-PCR analysis.

\subsection{UC Disease Monitor and Marker Analysis}

2.4.1. Monitoring of General Health Conditions of Rats. Rats were monitored for their demeanor, food and water intake, body weight, appearance of fur, responsiveness, activity, appearance of feces, and other body conditions.

2.4.2. Morphological and Histopathological Examination of Rat Colon Mucosa. The colon tissue from the anus to the ileocecal region was dissected and its gross morphology was examined by eye. Tissue sections were stained by $\mathrm{H}+\mathrm{E}$ and observed under an optical microscope to further examine the morphology of rat colonic mucosa.

\subsubsection{Fluorescence Quantitative RT-PCR ( $q R T-P C R)$ Analysis.}

(1) RNA extraction: rat colon tissues were removed from liquid nitrogen, and $1 \mathrm{~mL}$ TRIzol Reagent was added to every $100 \mathrm{mg}$ of tissue. The tissue was homogenized twice for $15 \mathrm{~s}$ each, with a $10 \mathrm{~s}$ interval. $0.2 \mathrm{~mL}$ chloroform was added per $1 \mathrm{~mL}$ TRIzol Reagent, and then this mixture was vigorously shaken for $15 \mathrm{~s}$, cooled on ice for $5 \mathrm{~min}$, and centrifuged at $12,000 \mathrm{rpm}$ and $4^{\circ} \mathrm{C}$ for $15 \mathrm{~min}$ in a microcentrifuge (Thermo, US). The upper aqueous phase was taken into another microcentrifuge tube, and an equal volume of prechilled isopropanol was added. The two solutions were slowly mixed, cooled on ice for 15-20 min, and then centrifuged at $12,000 \mathrm{rpm}, 4^{\circ} \mathrm{C}$ for $10 \mathrm{~min}$. The pellet was washed with $75 \%$ ethanol (DEPC-water : ethanol $=1: 3$ ) and centrifuged again at $7,500 \mathrm{rpm}, 4^{\circ} \mathrm{C}$ for $8 \mathrm{~min}$. The supernatant was removed, and the tubes were blotted dry on sterilized filter paper. The pellet was washed again, the ethanol was removed, and the pellet was air-dried. After the pellet was dry; it was dissolved in DEPC-water. Then $1 \mathrm{~mL}$ of total RNA solution was used to determine RNA concentration and purity using NanoDrop. (2) Primer design and synthesis: primer 5 software was used to design qRT-PCR primers for the genes TLR2, IRAK1, IKK- $\beta$, and $\beta$-actin (Table 1). Primers were synthesized and purified by Sangon Biotech (Shanghai, China). (3) cDNA synthesis by one-step reverse transcription: here, $16.0 \mu \mathrm{L}$ $5 \mathrm{x}$ iScript reaction mix, $4.0 \mu \mathrm{L}$ iScript reverse transcriptase, $4 \mu \mathrm{g}$ total RNA (volume depends on the concentration), and $60.0 \mu \mathrm{L}$ DEPC- $\mathrm{H}_{2} \mathrm{O} 60.0 \mu \mathrm{L}$ were added to each $0.5 \mathrm{~mL}$ RNase-free centrifuge tube to a total reaction volume of $80 \mu \mathrm{L}$. The reaction program was as follows: $25^{\circ} \mathrm{C}$ for $5 \mathrm{~min}$, $42^{\circ} \mathrm{C}$ for $30 \mathrm{~min}$, and $85^{\circ} \mathrm{C}$ for $5 \mathrm{~min}$. (4) qPCR reaction: here, $1.0 \mu \mathrm{L}$ iQ SYBR Green Supermix, $1.0 \mu \mathrm{L}$ cDNA, $1.0 \mu \mathrm{L}$ each sense and antisense primer, and $8 \mu \mathrm{L}$ ddH $_{2} \mathrm{O}$ were added to each well of $0.2 \mathrm{~mL} 96$-well PCR plates. The plates were centrifuged briefly and placed into a PCR machine (LC96 PCR system, Roche, Switzerland) for amplification. The PCR 
TABLE 1: The gene sequences of the primers.

\begin{tabular}{lclc}
\hline ID & Primer name & Sequence $\left(5^{\prime}\right.$ to $\left.3^{\prime}\right)$ & Base number \\
\hline gi|392350511|ref|XM_003750630.1| & TLR2-domain & CCCAAGCACACTCACTCAACT & 20 \\
gi|189011593|ref|NM_001127555.1| & IRAK-1 & CAAGGAGGCACTACCAGAGAAT & 22 \\
gi|158508715|ref|NM_053355.2| & IKK- $\beta$ & CCAAGAGACCAAAGGACAGAAG & 22 \\
\hline
\end{tabular}

program was (1) $95^{\circ} \mathrm{C}$ for $5 \mathrm{~min}$ and (2) 40 cycles of $95^{\circ} \mathrm{C}$ for $10 \mathrm{~s}, 58^{\circ} \mathrm{C}$ for $30 \mathrm{~s}$, and $72^{\circ} \mathrm{C}$ for $10 \mathrm{~s}$.

2.4.4. Immunohistochemical Detection of TLR2, IRAK1, IKK$\beta, N F-\kappa B, I F N-\beta$, and IL-10 Proteins in Colonic Mucosa. Tissue sections were deparaffinized with the following solutions: three changes of xylene, each lasting for $10 \mathrm{~min}: 100 \%$, 95\%, and $85 \%$; $75 \%$ ethanol for $2 \mathrm{~min}$ and then placing in water. Sections were washed three times with $0.01 \mathrm{M}$ PBS ( $\mathrm{pH}$ 7.4) for 3 min each and then incubated with $1 \% \mathrm{H}_{2} \mathrm{O}_{2}$ for $20 \mathrm{~min}$. Then they were washed three times in PBS for 3 min each and three distilled water washes, $3 \mathrm{~min}$ each. Sections were incubated with PBS for $5 \mathrm{~min}$ and then subjected to antigen retrieval. For antigen retrieval, the sections were placed in $0.01 \mathrm{M}$ citrate buffer ( $\mathrm{pH} 6.0$ ) and boiled three times in a microwave at setting III $\left(98^{\circ} \mathrm{C}\right.$ ) for $2.5 \mathrm{~min}, 1.5 \mathrm{~min}$, and $1 \mathrm{~min}$, respectively. Sections were kept in the hot buffer for $15 \mathrm{~min}$ each between rounds of boiling. Sections were let to cool at room temperature and then washed twice with distilled water, followed by three washes with PBS, 3 min each. Sections were blocked in 5\% goat serum at room temperature for $20 \mathrm{~min}$ and then incubated with diluted primary antibodies (30$50 \mu \mathrm{L})$ at $4^{\circ} \mathrm{C}$ overnight. The next day, sections were washed three times with PBS for 3 min each and then incubated with biotinylated secondary antibody-EnVision reagent (30$50 \mu \mathrm{L}$ ) for $30 \mathrm{~min}$ at $37^{\circ} \mathrm{C}$, followed by three washes with PBS, 3 min each. To allow visualization of bound antibodies, sections were incubated with $0.04 \% \mathrm{DAB}+0.03 \% \mathrm{H}_{2} \mathrm{O}_{2}$ for $8 \mathrm{~min}$ for color development. Sections were washed in water, counterstained with hematoxylin for $30 \mathrm{~s}$, washed again with water, dipped in a bluing solution containing hydrochloric acid and ethanol for $2 \mathrm{~s}$, washed in water, and mounted with resin.

Stained sections were examined under a light microscope. Positive staining was brown, and counterstained nuclei were blue. Three randomly chosen microscopic fields were analyzed with the MOTIC image analysis system. Total area and integrated optical density of positive signals were measured for each field, and the mean values from the three fields of each sample were used for statistical analysis.

2.5. Statistical Analysis. Quantitative data are here presented as mean \pm standard deviation $(\bar{x} \pm s)$, and statistical analysis was performed with the PASS 13.0 software. Comparisons between groups were conducted using one-way ANOVA with the following methods: LSD/SNK-q method was used when pairwise tests showed that the variances of different groups were equal, but Dunnett's T3 method was used when the variances were not equal. The level of significance was set to $\alpha=0.05$ and $P<0.05$.

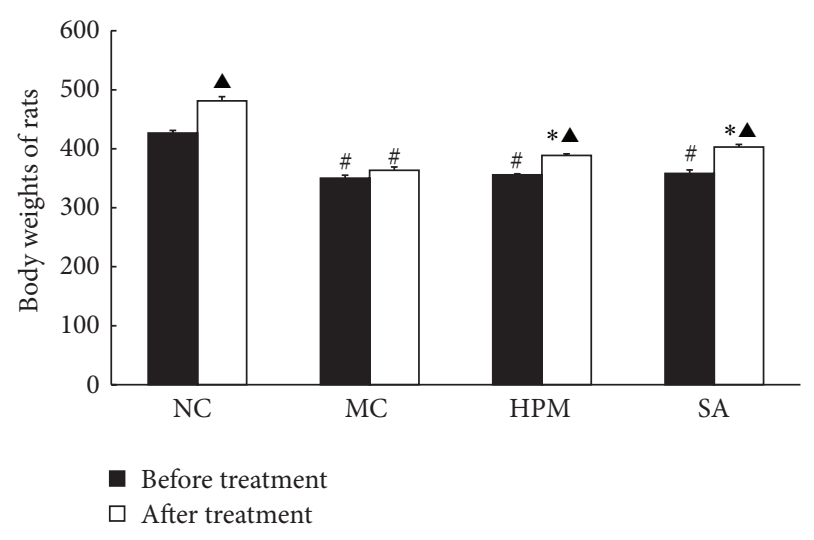

FIGURE 1: The body weights of rats in each group. NC: normal control; MC: ulcerative colitis; HPM: UC with herb-partitioned moxibustion; SA: UC with salicylazosulfapyridine. ${ }^{\#} P<0.01$ versus NC; ${ }^{*} P<0.01$ versus $M C ;{ }^{\mathbf{A}} P<0.01$ versus before treatment.

\section{Results}

3.1. General Health Conditions of Rats in the Experimental Groups. Rats in the control group had normal food and water intake, were active, and had dense and shiny pelts. UC rats showed debility and anorexia, their food intake was reduced, and they had a hunched posture. They showed reduced activity levels and were easily startled. Their feces appeared normal and their perianal skin remained clean. Their coats appeared rough and less shiny. They had increased stool frequency, bloody mucus was seen in the feces, and the perianal skin was dirty with feces. The toes injected with antigen were bruised and swollen. One rat in this group died during the experimental period. Rats in the herb-partitioned moxibustion and SASP treatment groups displayed better food intake, responsiveness, activity levels, and appearance of the fur coat than rats in the UC group.

As shown in Figure 1, rats in the control group gained significantly weight by the end of the experimental period $(P<0.01)$. The body weights of UC rats were significantly lower than those of the control rats $(P<0.01)$. The body weights of rats in the herb-partitioned moxibustion and SASP treatment groups were greater than those of rats in the UC group $(P<0.01)$.

3.2. Macro- and Microscopic Morphology of Rat Colonic Mucosa. Observed by the naked eye, the colonic mucosa of control rats had a smooth surface with small amounts of mucus. The blood vessels underneath the mucosal folds were visible, and there was no erosion or ulceration. The colonic mucosa of UC rats had severe hyperemia, edema, and 




(a)

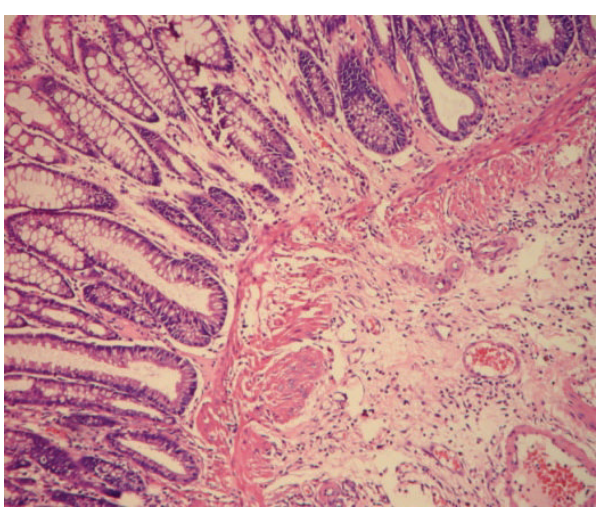

(c)

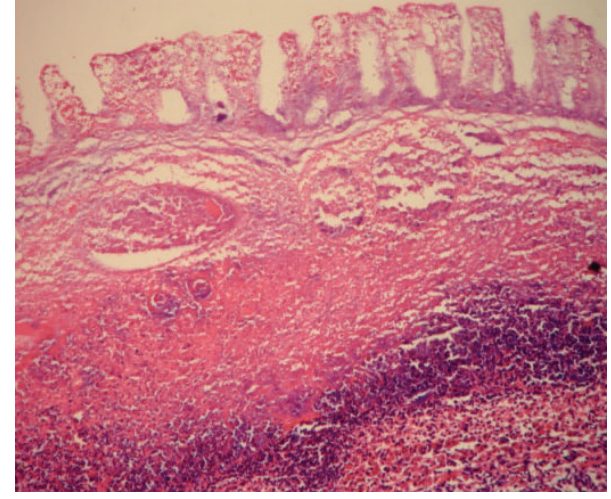

(b)

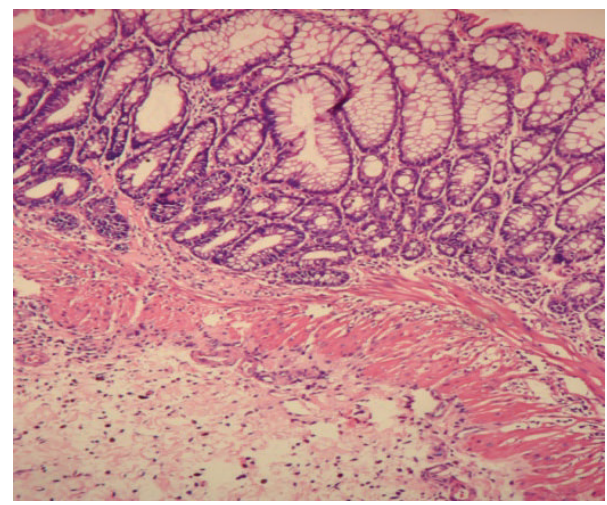

(d)

Figure 2: The histological observation of rats in each group. Hematoxylin-Eosin staining method, $\times 200$. (a) Normal control; (b) ulcerative colitis; (c) UC with herb-partitioned moxibustion; (d) UC with salicylazosulfapyridine.

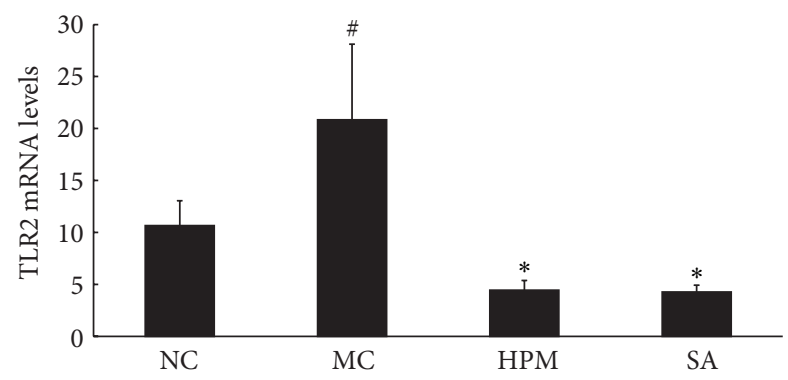

FIGURE 3: The TLR2 mRNA levels in the rat colon of each group. NC: normal control; MC: ulcerative colitis; HPM: UC with herbpartitioned moxibustion; SA: UC with salicylazosulfapyridine. ${ }^{\#} P<$ 0.01 versus $\mathrm{NC} ;{ }^{*} P<0.01$ versus $\mathrm{MC}$.

erosion, and ulcers were observed. In contrast, the appearance of colonic mucosa from rats in the herb-partitioned moxibustion and SASP treatment groups was markedly better than those of other groups. Even though the mucosal surface was not as smooth as in normal mucosa and there was some visible edema, the muscles under the mucosal folds were visible and the extent of hyperemia, edema, and erosion of the mucosa was significantly less pronounced than in UC rats.

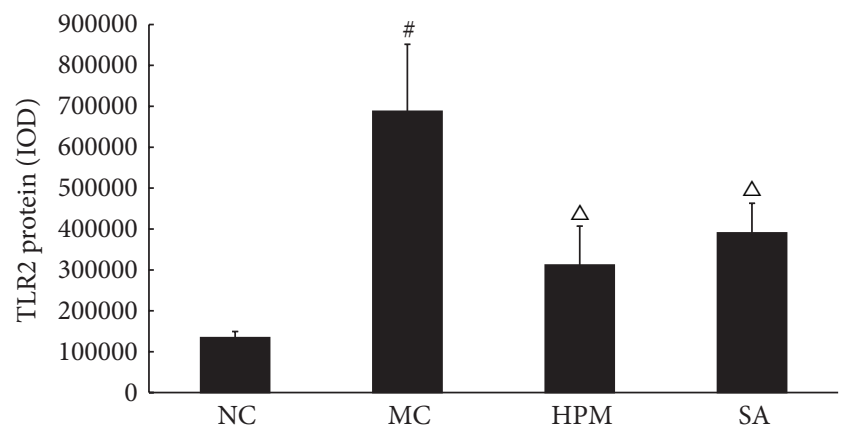

FIGURE 4: Expression of TLR2 protein in the colonic mucosa of rat. NC: normal control; MC: ulcerative colitis; HPM: UC with herbpartitioned moxibustion; SA: UC with salicylazosulfapyridine. ${ }^{\sharp} P<$ 0.01 versus $\mathrm{NC} ;{ }^{\triangle} P<0.05$ versus MC.

As shown in Figure 2, under a light microscope, normal colonic mucosa had a well-organized structure with intestinal glands arranged in rows and an intact colonic epithelium. Capillaries and scattered lymphocytes were visible in the lamina propria, but there was no significant inflammatory cell infiltration. In the colonic mucosa of UC rats, the crypts were shorter and the epithelium was not intact. The mucosa and submucosa had been infiltrated by a large number of 


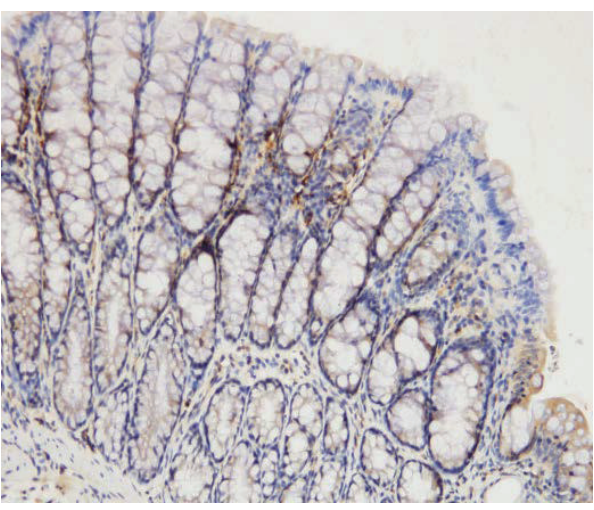

(a)

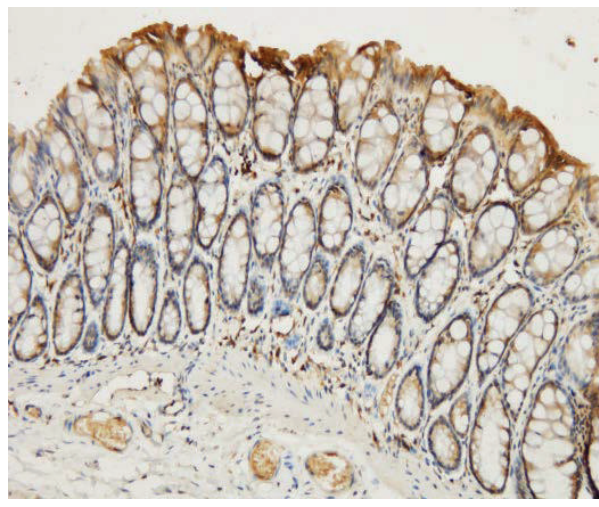

(c)

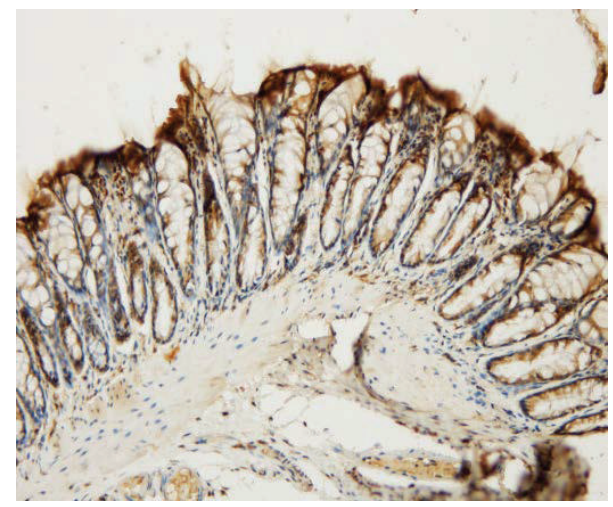

(b)

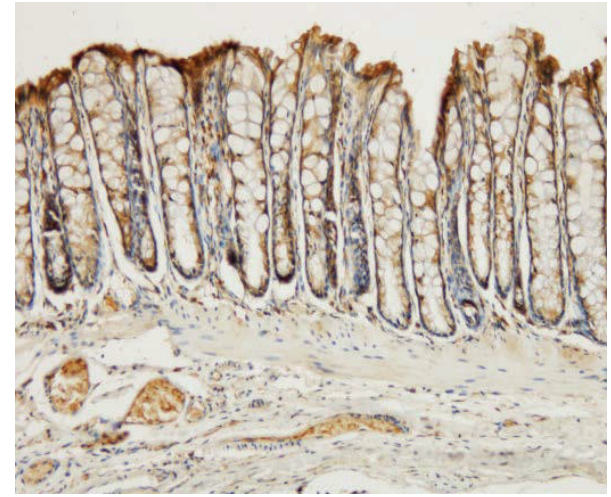

(d)

FIgURE 5: The integral optical density (IOD) of TLR2 in each rat group. EnVision Plus method, $\times 200$. (a) Normal control; (b) ulcerative colitis; (c) UC with herb-partitioned moxibustion; (d) UC with salicylazosulfapyridine.

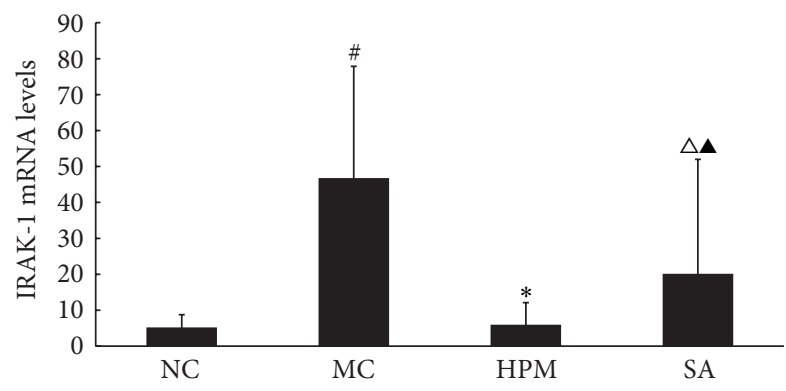

FIGURE 6: The IRAK-1 mRNA levels in the rat colon of each group. NC: normal control; MC: ulcerative colitis; HPM: UC with herbpartitioned moxibustion; SA: UC with salicylazosulfapyridine. ${ }^{\#} P<$ 0.01 versus $\mathrm{NC} ;{ }^{*} P<0.01,{ }^{\triangle} P<0.05$ versus $\mathrm{MC} ;{ }^{\wedge} P<0.01$ versus HPM.

inflammatory cells, focal hyperemia and edema were visible, and the structures of the glands were disorganized, indicating that ulcers had formed. Both herb-partitioned moxibustion and SASP treatments greatly improved the morphology of colonic mucosa. Intestinal glands were more organized than those in UC rats. Ulceration was less severe, and the mucosa surface was covered by epithelial cells. Edema and inflammatory cell infiltration in submucosa were still present, but they were less severe than in UC rats.

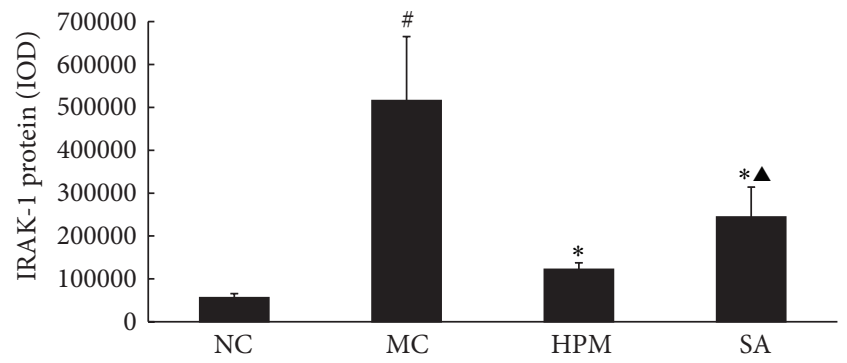

FIgURE 7: Expression of IRAK-1 protein in the colonic mucosa of rat. NC: normal control; MC: ulcerative colitis; HPM: UC with herbpartitioned moxibustion; SA: UC with salicylazosulfapyridine. ${ }^{\#} P<$ 0.01 versus $\mathrm{NC} ;{ }^{*} P<0.01$ versus $\mathrm{MC} ;{ }^{\mathbf{}} P<0.01$ versus $\mathrm{HPM}$.

3.3. TLR2 $m R N A$ and Protein Expression in Rat Colonic Mucosa. As shown in Figure 3, TLR2 mRNA level in the colonic mucosa was significantly higher in the UC rats than in the control rats $(P<0.01)$. Both herb-partitioned moxibustion and SASP treatments significantly reduced TLR2 mRNA expression in the colonic mucosa of UC rats $(P<0.01)$. This inhibitory effect was slightly greater with SASP treatment than with herb-partitioned moxibustion, but the difference was not statistically significant $(P>0.05)$. 


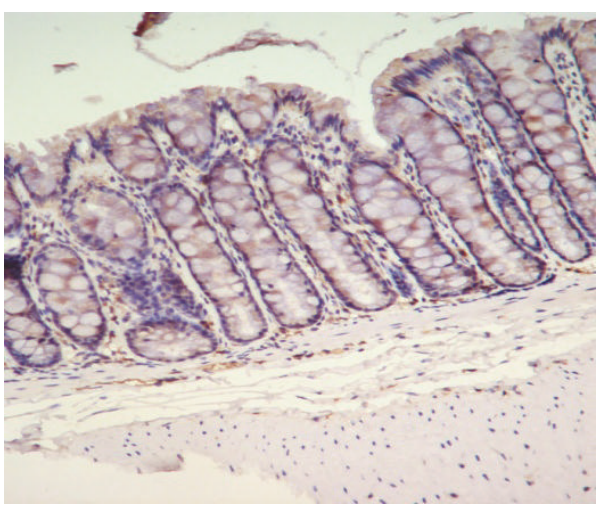

(a)

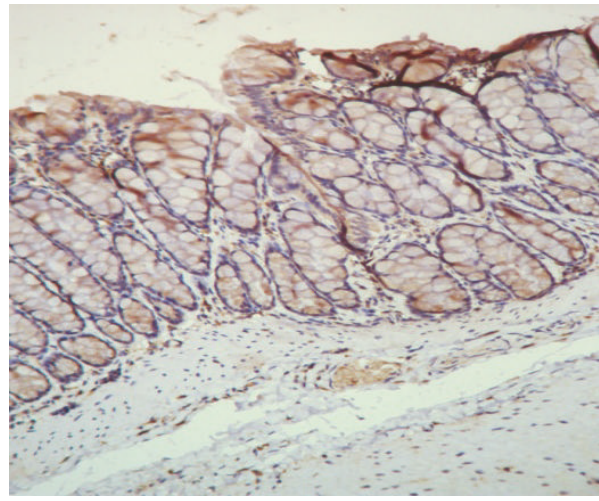

(c)

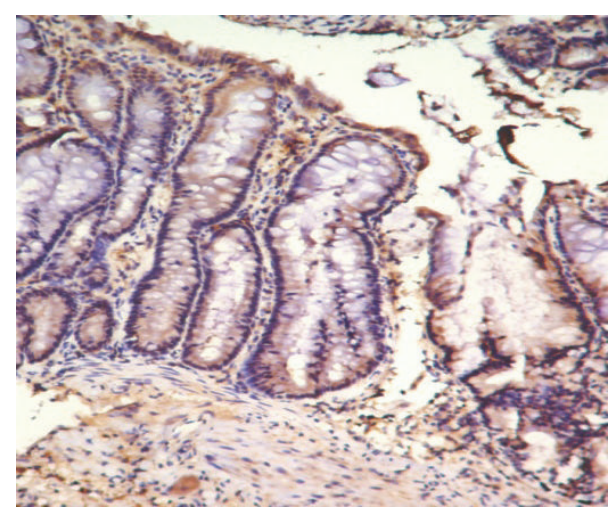

(b)



(d)

FIGURE 8: The integral optical density (IOD) of IRAK-1 in each rat group. EnVision Plus method, $\times 200$. (a) Normal control; (b) ulcerative colitis; (c) UC with herb-partitioned moxibustion; (d) UC with salicylazosulfapyridine.



FIgURE 9: The IKK- $\beta$ mRNA levels in the rat colon of each group. NC: normal control; MC: ulcerative colitis; HPM: UC with herbpartitioned moxibustion; SA: UC with salicylazosulfapyridine. ${ }^{\#} P<$ 0.01 versus $\mathrm{NC} ;{ }^{*} \mathrm{P}<0.01$ versus MC.

TLR2 protein expression was determined using immunohistochemistry and quantified by the total area of staining and the integrated optical density. As shown in Figures 4 and 5 , TLR2 protein levels in the colonic mucosa were higher in UC rats than in control rats, as indicated by both of these measurements $(P<0.01)$. The total area of TLR2 staining was significantly lower in both the herb-partitioned moxibustion and SASP treated groups than in the UC group $(P<0.01, P<$ $0.05)$. The integrated optical density was also significantly lower in both treatment groups $(P<0.05)$. TLR2 protein

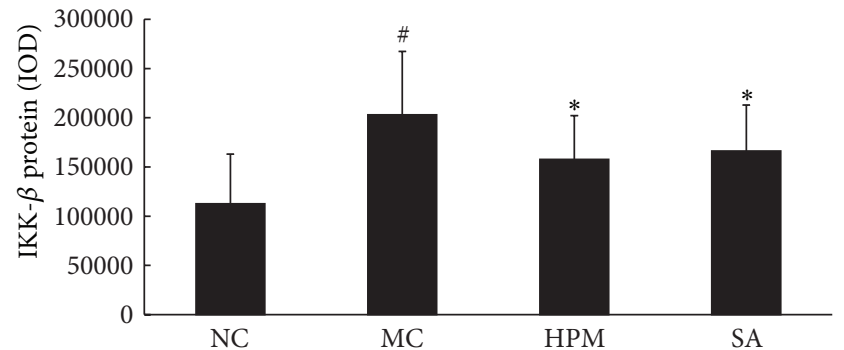

FIGURE 10: Expression of IKK- $\beta$ protein in the colonic mucosa of rat. NC: normal control; MC: ulcerative colitis; HPM: UC with herbpartitioned moxibustion; SA: UC with salicylazosulfapyridine. ${ }^{\#} P<$ 0.01 versus $\mathrm{NC} ;{ }^{*} P<0.01$ versus $\mathrm{MC}$.

levels were slightly lower in the herb-partitioned moxibustion group than in the SASP group, but the difference was not statistically significant $(P>0.05)$.

3.4. IRAK1 mRNA and Protein Expression in Rat Colonic Mucosa. As shown in Figure 6, rats in the UC group expressed significantly higher levels of IRAK1 mRNA in the colonic mucosa than rats in the control group $(P<0.01)$. Both herb-partitioned moxibustion and SASP treatments significantly reduced IRAK-1 mRNA expression in the colonic 


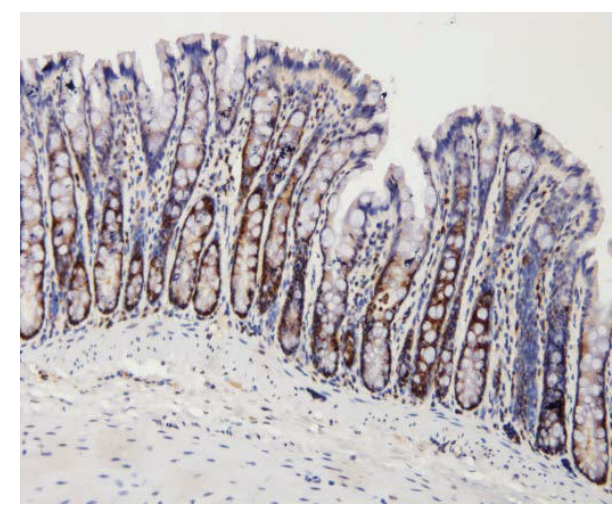

(a)

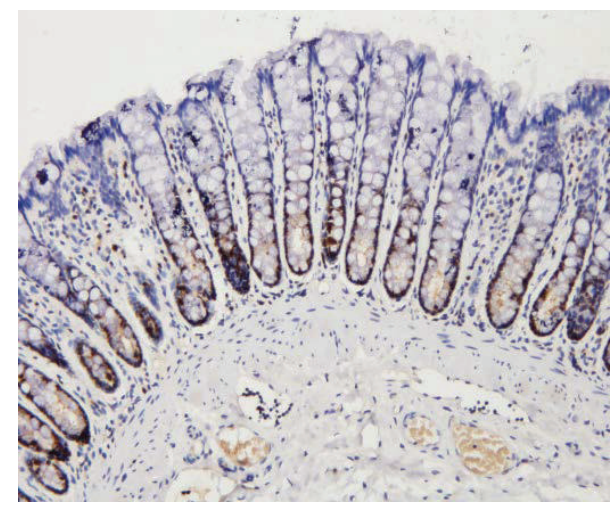

(c)

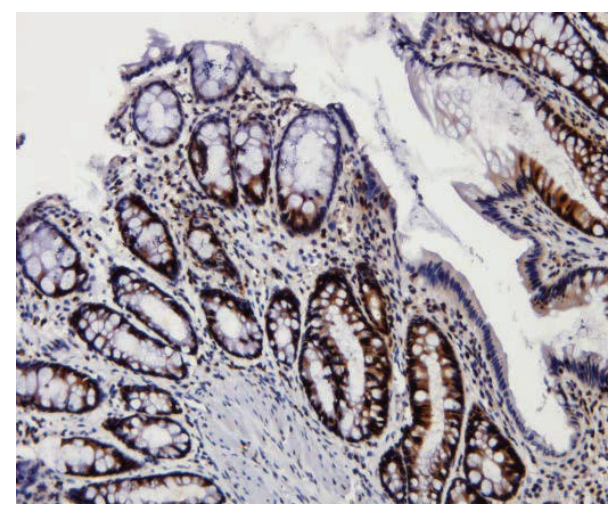

(b)

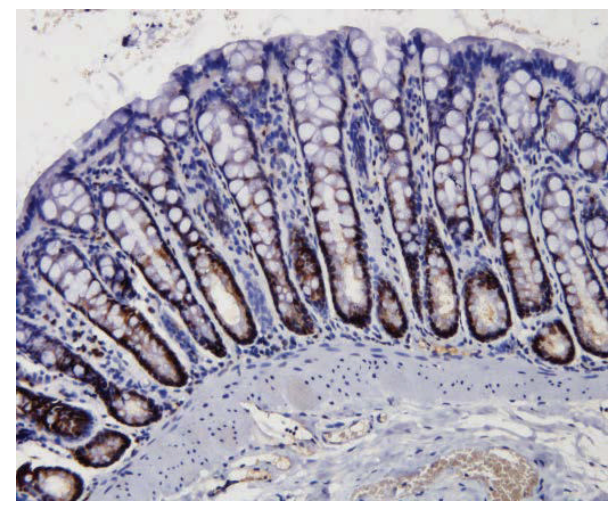

(d)

FIgURE 11: The integral optical density (IOD) of IKK- $\beta$ in each rat group. EnVision Plus method, $\times 200$. (a) Normal control; (b) ulcerative colitis; (c) UC with herb-partitioned moxibustion; (d) UC with salicylazosulfapyridine.

mucosa of UC rats $(P<0.01, P<0.05)$. Between the two treatment groups, IRAK1 mRNA expression in the colonic mucosa was significantly higher with SASP than with herbpartitioned moxibustion treatment $(P<0.01)$.

As shown in Figures 7 and 8, IRAK1 protein levels in the colonic mucosa were significantly higher in UC rats than in the control rats, as measured by both the total area of staining and the integrated optical density $(P<0.01$ in both cases). Both herb-partitioned moxibustion and SASP treatments significantly reduced IRAK1 protein levels in the colonic mucosa of UC rats, as indicated by both of these measurements $(P<0.01$ in all cases). IRAK1 protein levels in the colonic mucosa were significantly lower in the herbpartitioned moxibustion than in the SASP treatment by both of these measurements ( $P<0.01$ in both cases).

\subsection{IKK- $\beta$ mRNA and Protein Expression in Rat Colonic} Mucosa. As shown in Figure 9, rats in the UC group expressed significantly higher levels of IKK- $\beta$ mRNA in the colonic mucosa than rats in the control group $(P<0.01)$. Both herb-partitioned moxibustion and SASP treatments significantly reduced IKK- $\beta$ mRNA expression in the colonic mucosa of UC rats $(P<0.01)$.

As shown in Figures 10 and 11, IKK- $\beta$ protein levels in the colonic mucosa were significantly higher in UC rats than in the control rats, as measured by both the total area

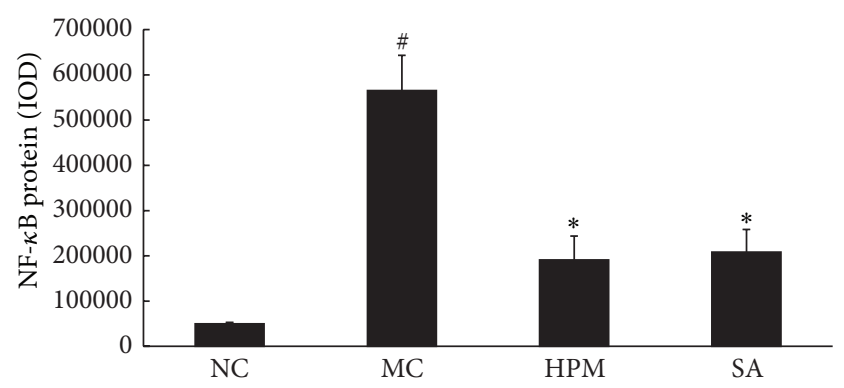

FIgURE 12: Expression of NF- $\kappa$ B protein in the colonic mucosa of rat. NC: normal control; MC: ulcerative colitis; HPM: UC with herbpartitioned moxibustion; SA: UC with salicylazosulfapyridine. ${ }^{\#} P<$ 0.01 versus $\mathrm{NC} ;{ }^{*} P<0.01$ versus MC.

of staining and the integrated optical density $(P<0.05$, $P<0.01)$. Both herb-partitioned moxibustion and SASP treatments significantly reduced IKK- $\beta$ protein levels in the colonic mucosa of UC rats, as indicated by both of these measurements $(P<0.05)$.

3.6. NF- $\kappa B$ Expression in Rat Colonic Mucosa. As shown in Figures 12 and $13, \mathrm{NF}-\kappa \mathrm{B}$ protein levels in the colonic mucosa were significantly higher in UC rats than in the control 


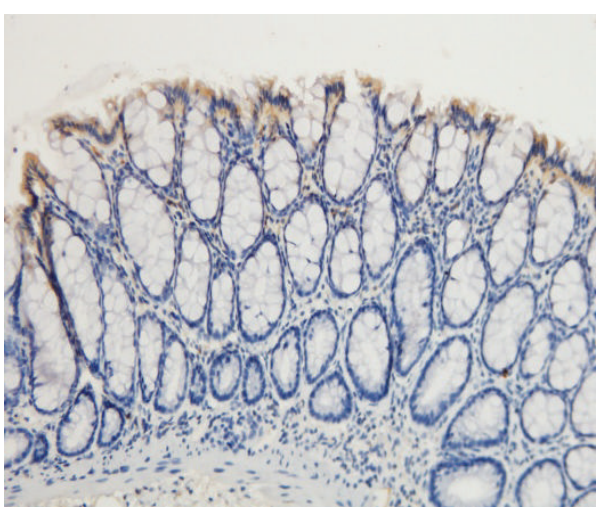

(a)

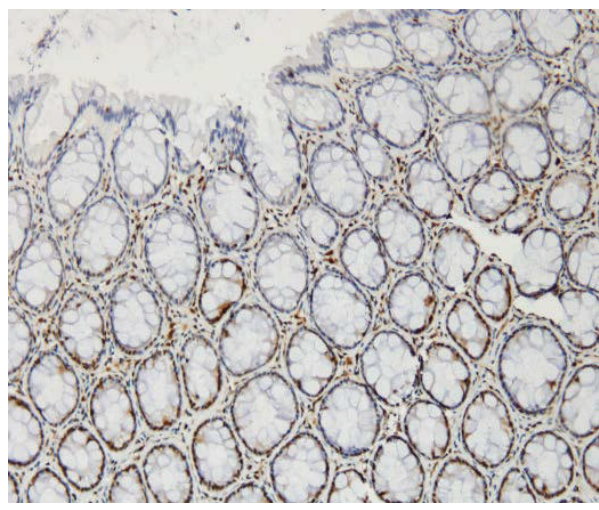

(c)

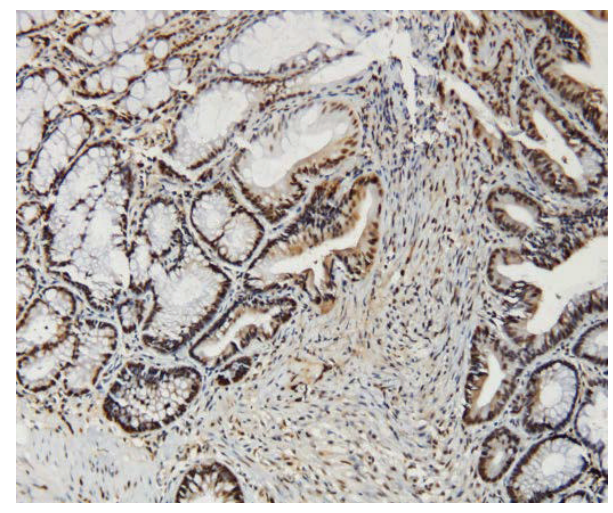

(b)

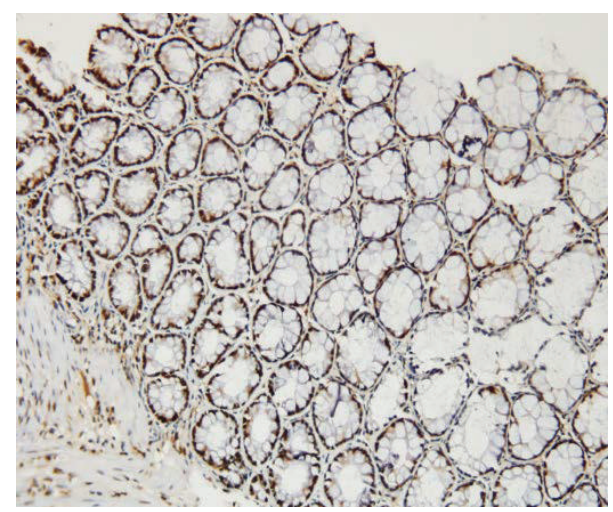

(d)

FIgURE 13: The integral optical density (IOD) of NF- $\kappa$ B in each rat group. EnVision Plus method, $\times 200$. (a) Normal control; (b) ulcerative colitis; (c) UC with herb-partitioned moxibustion; (d) UC with salicylazosulfapyridine.

rats, as measured by both the total area of staining and the integrated optical density $(P<0.01)$. Both herb-partitioned moxibustion and SASP treatments were associated with lower $\mathrm{NF}-\kappa \mathrm{B}$ protein levels in the colonic mucosa of UC rats as indicated by the total area of staining $(P<0.01)$. NF$\kappa \mathrm{B}$ protein levels were slightly lower in the herb-partitioned moxibustion group than in the SASP group, but the difference was not statistically significant $(P>0.05)$.

3.7. IFN- $\beta$ Expression in Rat Colonic Mucosa. As shown in Figures 14 and 15, IFN- $\beta$ protein levels in the colonic mucosa were significantly lower in UC rats than in the control rats, as indicated by both the total area of staining and the integrated optical density $(P<0.01$ in both cases). Both herbpartitioned moxibustion and SASP treatments significantly increased IFN- $\beta$ protein levels in the colonic mucosa of UC rats by both of these measurements $(P<0.01$ in both cases). Between the two treatment groups, IFN- $\beta$ protein levels in the colonic mucosa were significantly higher with herb-partitioned moxibustion than with SASP treatment as indicated by both of these measurements $(P<0.05$ in both cases).

3.8. IL-10 Expression in Rat Colonic Mucosa. As shown in Figures 16 and 17, IL-10 protein levels in the colonic mucosa were significantly lower in UC rats than in the control



FIGURE 14: Expression of IFN- $\beta$ protein in the colonic mucosa of rat. NC: normal control; MC: ulcerative colitis; HPM: UC with herbpartitioned moxibustion; SA: UC with salicylazosulfapyridine. ${ }^{\#} P<$ 0.01 versus $\mathrm{NC} ;{ }^{*} P<0.01$ versus $\mathrm{MC} ;{ }^{\wedge} P<0.01$ versus HPM.

rats, as indicated by both the total area of staining and the integrated optical density $(P<0.05$ in both cases). Both herbpartitioned moxibustion and SASP treatments significantly increased IL-10 protein levels in the colonic mucosa of UC rats by both of these measurements $(P<0.05$ in all cases). The total area of IL-10 staining in the colonic mucosa was significantly higher in the herb-partitioned moxibustion group than in the SASP group $(P<0.05)$ but the integrated optical density did not reach statistical significance, although 


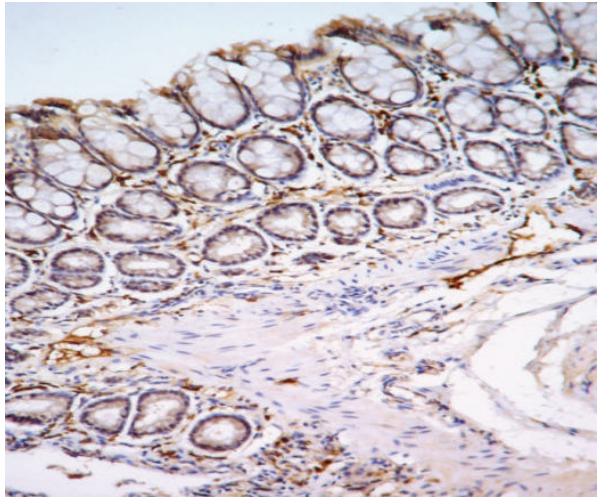

(a)

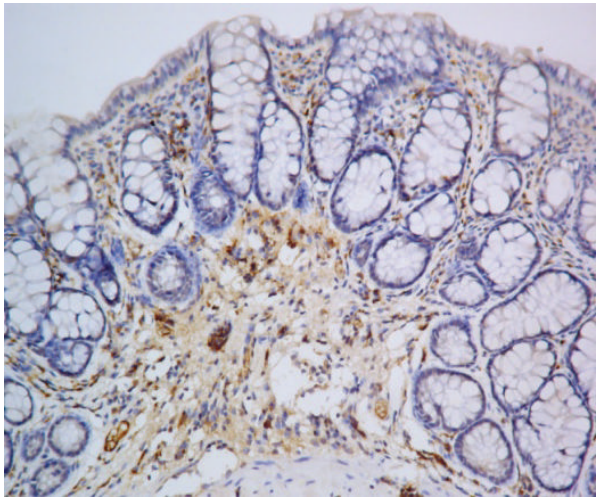

(c)

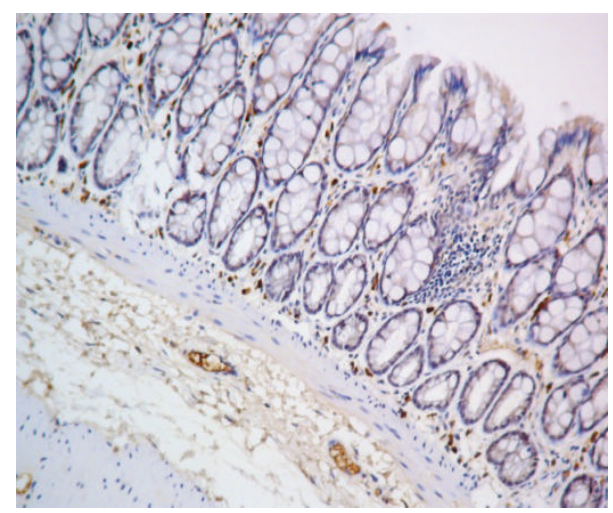

(b)



(d)

FIgURE 15: The integral optical density (IOD) of IFN- $\beta$ in each rat group. EnVision Plus method, $\times 200$. (a) Normal control; (b) ulcerative colitis; (c) UC with herb-partitioned moxibustion; (d) UC with salicylazosulfapyridine.



FIGURE 16: Expression of IL-10 protein in the colonic mucosa of rat. NC: normal control; MC: ulcerative colitis; HPM: UC with herbpartitioned moxibustion; SA: UC with salicylazosulfapyridine. ${ }^{\#} P<$ 0.01 versus $\mathrm{NC} ;{ }^{*} P<0.01$ versus $\mathrm{MC}$.

it was higher in the herb-partitioned moxibustion group than in the SASP group $(P>0.05)$.

\section{Discussion}

According to its clinical manifestations in the traditional Chinese medicine, ulcerative colitis belongs to scope of "diarrhea" and "abdominal pain." It occurs in the large intestine, but the basic pathogenesis is spleen deficient and hyperactivity of damp. Tianshu (ST25) acupoint, located at 2 inches next to navel of the stomach channel of foot-yangming, is the $\mathrm{Mu}$ point of large intestine, it is a key point regulating the ascending and descending Qi and is usually used to treat the abdominal pain and diarrhea [18], and it was recorded in ancient medical books, such as "Qianjin Yaofang." Qihai (CV6) acupoint is located at 1.5 inches below navel of Ren meridian and the place gathering original Qi; it can regulate the ascending and descending Qi and complement original Qi of the human body. Therefore, moxibustion at ST25 and CV6 can improve the symptoms of diarrhea and abdominal pain in patient with ulcerative colitis, not only regulating $\mathrm{Qi}$ and reinforcing spleen and transporting dampness, but also complementing original Qi to promote recovery of patient.

Ulcerative colitis is associated with multiple aspects of immune dysfunction, including autoimmunity and dysregulated humoral and cellular immunity. It has been recognized that immune dysfunction plays an important role in the pathogenesis of UC [19-22].

The activation of TLR signaling pathways is involved in the development of UC. TLR2 activates NF- $\kappa \mathrm{B}$ through the MyD88-dependent pathway [23]. Activated NF- $\kappa$ B induces the expression of TLR2 transcriptionally, resulting in a TLR2NF- $\kappa$ B-TLR2 positive feedback loop that propagates the inflammatory response [24]. The IRAK1 family protein acts 


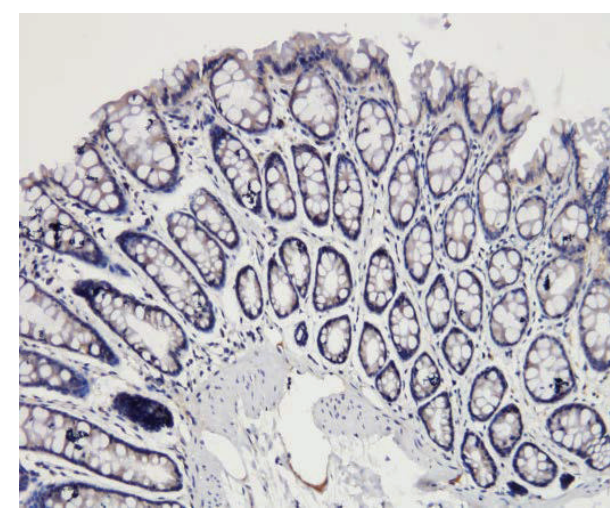

(a)

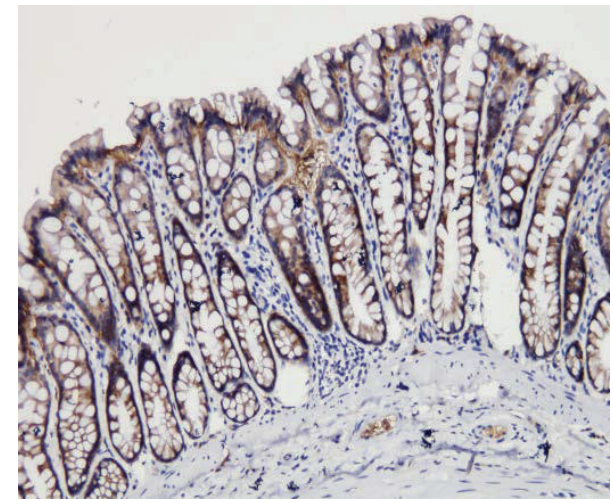

(c)

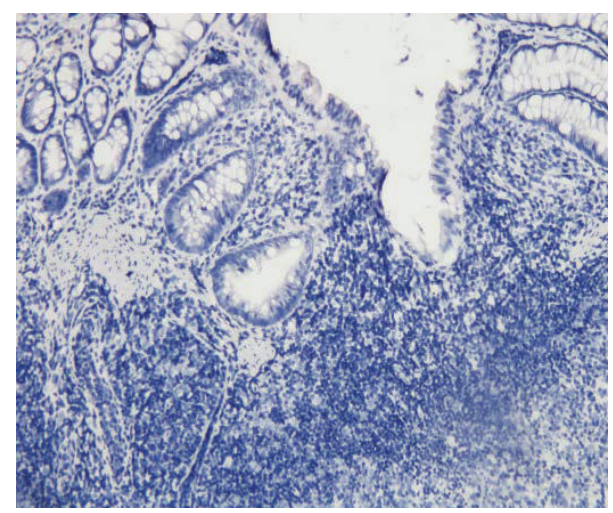

(b)

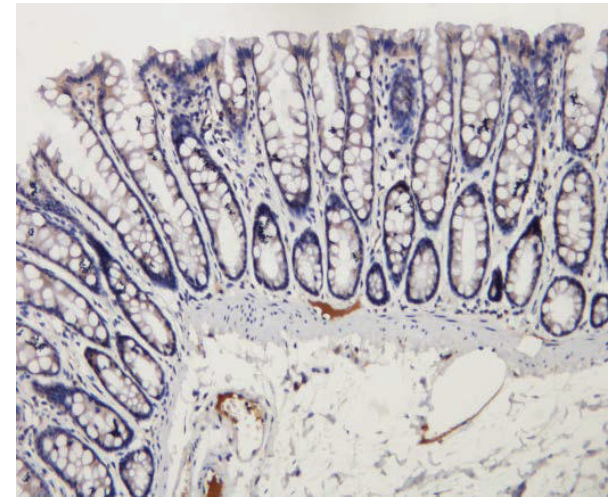

(d)

FIgURE 17: The integral optical density (IOD) of IL-10 in each rat group. EnVision Plus method, $\times 200$. (a) Normal control; (b) ulcerative colitis; (c) UC with herb-partitioned moxibustion; (d) UC with salicylazosulfapyridine.

as an adaptor protein and mediates TLR-induced production of proinflammatory cytokines. Degradation of IRAK1 comprises an important negative feedback mechanism that prevents excessive inflammation $[25,26]$. The IKK $\beta / N F-\kappa B$ signaling pathway plays key roles in inducing the immune response downstream of TLRs. IKK- $\beta$ is an essential catalytic subunit of the protein complex that activates $\mathrm{NF}-\kappa \mathrm{B}$ in response to inflammatory cytokines, such as TNF- $\alpha$, IL- 1 , and lipopolysaccharide. Studies have shown that TLR2 expression is low in epithelial cells of normal intestinal mucosa but becomes high during inflammation [27]. Abnormally high expression of TLR2 was observed in the colonic mucosa of patients with UC and in mouse models of UC [28, 29]. In addition, the DNA binding activity of NF- $\kappa \mathrm{B}$ in cell nucleus was found to be higher in the colonic mucosa of patients with UC $[30,31]$. These discoveries suggest that the activation of the TLR2/NF- $\kappa \mathrm{B}$ signaling pathway is closely associated with the development of UC.

Proinflammatory cytokines TNF- $\alpha$ and IL-12 and antiinflammatory cytokines IL-10 and IFN- $\beta$ play important roles in the pathogenesis of UC. In the presence of IL- 6 and TNF$\alpha$ causes microvascular dysfunction in the intestinal mucosa, damaging its barrier function. TNF- $\alpha$ also acts synergistically with IFN- $\gamma$ to alter the structure and the barrier function of the intestinal mucosal epithelium, leading to increased permeability of the colonic mucosa and apoptosis of epithelial cells [32]. IL-12 stimulates the differentiation of T cells into IFN- $\gamma$-secreting T-helper type 1 (Th1) cells, which promotes inflammation by activating macrophages and neutrophils [24]. IL-10 is mainly produced by Th2 cells, activated B cells, monocytes, and macrophages. It dampens immune responses by antagonizing inflammatory mediators. IFN- $\beta$ is a cytokine produced by fibroblasts and white blood cells. It can inhibit the proliferation of fibroblasts, epithelial cells, endothelial cells, and hematopoietic cells [33]. IFN- $\beta$ plays an immunoregulatory role by promoting the secretion of IL-10 and T lymphocytes [34]. Studies have shown that the levels of IL-12 and TNF- $\alpha$ are significantly increased in the peripheral blood of patients with IBD $[25,26,35]$. The expression of IL-12 mRNA in the colonic mucosa of patients with UC is significantly higher during the active phase of the disease, and the degree of the increase correlates with the severity of the disease [36, 37]. Genomewide association studies have identified an association between polymorphisms of IL-10 and increased susceptibility to IBD [38-40]. The function of anti-inflammatory macrophages is altered in IL-10R-deficient patients with IBD [41]. IL-10 expression in colonic epithelial cells is elevated in patients with UC [42]. A study showed that IFN- $\beta$ suppressed inflammation induced by high levels of IL-13 in patients with UC [43]. Another study showed that natural IFN- $\beta$ was effective in treating patients with active, steroid refractory UC [44]. In this way, inhibiting 
the TLR2/NF- $\kappa \mathrm{B}$ signaling pathway by modulating the key mediators of this pathway, such as TLR2, IRAK1, IKK- $\beta$, and $\mathrm{NF}-\kappa \mathrm{B}$, and downstream effector cytokines, such as TNF- $\alpha$, IL-12, IL-10, and IFN- $\beta$, may provide effective treatments for UC.

Herb-partitioned moxibustion is beneficial for patients with UC [45]. This treatment can reduce the expression of IL- 8 and ICAM-1 mRNA and proteins in the colonic mucosa of patients with UC [46]. Previous studies have found that IL -12 and TNF- $\alpha$ expressions are significantly higher in UC rat colons, but herb-partitioned moxibustion reduces their expression [47]. Herb-partitioned moxibustion can also reduce the concentrations of IL- $1 \beta$, IL- 6 , and TNF- $\alpha$ from induced peripheral blood mononuclear cells (PBMCs) cultured supernatants of UC rats, relieving intestinal inflammation [48]. In the present study, results showed that, in UC rat colons, the normal mucosa structure was damaged and the levels of TLR2, IRAK1, and IKK- $\beta$ mRNA and proteins were significantly higher, and the levels of IL-10 and IFN$\beta$ proteins were significantly lower than those of the control rat colon. With herb-partitioned moxibustion treatment, the levels of TLR2, IRAK1, and IKK- $\beta$ mRNA and proteins were significantly lower, and the levels of IL-10 and IFN- $\beta$ proteins were significantly higher. These data suggest that the TLR2/NF- $\kappa$ B signaling pathway is involved in the development of UC, and herb-partitioned moxibustion can reverse the dysregulated expression of signaling molecules in the TLR2 pathway effectively, thereby inhibiting TLR2/NF- $\kappa \mathrm{B}$ pathway activation, modulating the local immune response in the colonic mucosa, protecting the mucosa, and promoting repair of injured mucosa.

\section{Conflict of Interests}

The authors declare that there is no conflict of interests regarding the publication of this paper.

\section{Authors' Contribution}

Xiaomei Wang, Yanan Liu, and Hongsheng Dong contributed equally to this paper.

\section{Acknowledgments}

The authors thank the support of Shanghai Health System of Outstanding Young Talent Cultivation Program (no. XYQ2011068), the National Natural Science Foundation of China (no. 81001549 and no. 81473758), National Basic Research Program of China (973 program, no. 2009CB522900), and Innovation Program of Shanghai Municipal Education Commission (no. 2014YZ052).

\section{References}

[1] G. H. Luo, X. Wang, and K. C. Wu, "Progress in stem cell therapy for inflammatory bowel disease," Chinese Journal of Gastroenterology, vol. 15, no. 11, pp. 641-645, 2010.
[2] Y. Liu, X. F. Li, and L. Tang, "Progress in Toll-like receptors mediated the intestinal immune," Chinese Journal of Microecology, vol. 21, no. 3, pp. 278-282, 2009.

[3] L. A. J. O’Neill, C. E. Bryant, and S. L. Doyle, “Therapeutic targeting of toll-like receptors for infectious and inflammatory diseases and cancer," Pharmacological Reviews, vol. 61, no. 2, pp. 177-197, 2009.

[4] X. Lin and J. Liu, "TLR4/MyD88/NF- $\kappa$ b signaling pathway and ulcerative colitis," Chinese Journal of Gastroenterology, vol. 18, no. 4, pp. 244-246, 2013.

[5] X. Liu, Y. W. Ding, and H. Lin, "Expression of TLR2, TLR3, TLR5 and TLR9 in colon of ulcerativecolitis mice," Chinese Journal of Modern Medicine, vol. 22, no. 22, pp. 19-22, 2012.

[6] S. J. Sun, "Progress in Toll-like receptor 2," Chongqing Medicine, vol. 37, no. 5, pp. 533-535, 2008.

[7] Y. J. Fan, J. T. Song, F. H. Pei et al., "Effect of valsartan on neointimal hyperplasia and TLR4 expression in carotid artery of balloon injured rat," Chinese Journal of Gastroenterology and Hepatology, vol. 23, no. 2, pp. 147-149, 2014.

[8] L. Wang, "Clinical research of moxibustion on the treatment of ulcerative colitis," Chinese Journal of Health Care and Medicine, vol. 12, no. 2, pp. 154-155, 2012.

[9] N. Xu, “Toll-like receptors, NF- $\kappa \mathrm{B}$ and inflammatory bowel disease," International Journal of Digestive Diseases, vol. 23, no. 5, pp. 264-267, 2003.

[10] H. G. Wu, Z. Huang, H. R. Liu et al., "Experimental study on influence of acupuncture and moxibustion therapy on apoptosis colonic epithelial cells ts of ulcerative colitis," Zhongguo Zhenjiu, vol. 25, no. 2, pp. 119-122, 2005.

[11] Z. Shi, X. P. Ma, H. G. Wu et al., "Rein rasearch on acupuncture regulating cox- 2 and IL- $1 \beta$ in colon tissue of rat with ulcerative colitis," Journal of Jiangxi University of Traditional Chinese Medicine, vol. 16, no. 3, pp. 38-40, 2004.

[12] N. Li, X. F. Zhang, and H. Y. Niu, "Expression of TLR2 in colon mucosa of ulcerative colitis," Chinese Journal of Digestive Endoscopy, vol. 25, no. 10, pp. 535-539, 2008.

[13] S. N. Liu, X. F. Lu, N. Sun et al., "Toll-like receptors 2 and 4 and nuclear factor- $\kappa \mathrm{B}$ in colonic mucosa of ulcerative colitis: expression and clinical significance," Journal of Shandong University (Health Sciences), vol. 50, no. 2, pp. 60-63, 2012.

[14] Y. P. Liu and Y. Q. Li, "Expression and significance of nuclear factor- $\kappa \mathrm{B}$ in ulcerative colitis," Chinese Journal of Gastroenterology, vol. 11, no. 2, pp. 103-106, 2006.

[15] P. Radwan, K. Radwan-Kwiatek, J. Tabarkiewicz, S. Radej, and J. Rolinski, "Enhanced phenotypic and functional maturation of monocyte-derived dendritic cells from patients with active crohn's disease and ulcerative colitis," Journal of Physiology and Pharmacology, vol. 61, no. 6, pp. 695-703, 2010.

[16] S. Y. Xu, R. L. Bian, and X. Chen, Pharmacology Experiment Methodology, People's Medical Publishing House, Beijing, China, 2002.

[17] Z. R. Li, Experimental Acupuncture Science, China Press of Traditional Chinese Medicine, Beijing, China, 2007.

[18] H. G. Wu, G. Ji, Z. Shi et al., Diagnosis and Treatment of Ulcerative Colitis in Traditional Chinese Medicine, Shanghai Scientific \& Technological Publishers, 2009.

[19] S. Watanabe, M. Yamakawa, T. Hiroaki, S. Kawata, and O. Kimura, "Correlation of dendritic cell infiltration with active crypt inflammation in ulcerative colitis," Clinical Immunology, vol. 122 , no. 3, pp. $288-297,2007$. 
[20] M. Zhao and F. Gao, "New progress in the pathogenesis of ulcerative colitis," Progress in Modern Biomedicine, vol. 10, no. 16, pp. 3160-3165, 2010.

[21] X. D. Zhao and W. Zhang, "Review on the pathogenesis of ulcerative colitis," Modern Medicine \& Health, vol. 24, no. 10, pp. 1501-1502, 2008.

[22] H. Shiroeda, T. Tahara, M. Nakamura et al., "Association between functional promoter polymorphisms of macrophage migration inhibitory factor (MIF) gene and ulcerative colitis in Japan," Cytokine, vol. 51, no. 2, pp. 173-177, 2010.

[23] Y. Liu, Y. Wang, M. Yamakuchi et al., "Upregulation of tolllike receptor 2 gene expression in macrophage response to peptidoglycan and high concentration of lipopolysaccharide is involved in NK-kappaB activation," Infection and Immunity, vol. 69, no. 5, pp. 2788-2796, 2001.

[24] P. Radwan, K. Radwan-Kwiatek, J. Tabarkiewicz, S. Radej, and J. Rolinski, "Enhanced phenotypic and functional maturation of monocyte-derived dendritic cells from patients with active Crohn's disease and ulcerative colitis," Journal of Physiology and Pharmacology, vol. 61, no. 6, pp. 695-703, 2010.

[25] J. Bauditz, S. Wedel, and H. Lochs, "Thalidomide reduces tumour necrosis factor- $\alpha$ and interleukin 12 production in patients with chronic active Crohn's disease," Gut, vol. 50, no. 2, pp. 196-200, 2002.

[26] Y. H. Shi, H. Liu, and C. Y. Guo, "Study on the immune modulator of patients with ulcerative colitis," Basic Research, vol. 1, no. 11, pp. 31-33, 2007.

[27] M. Bosani, S. Ardizzone, and G. B. Porro, "Biologic targeting in the treatment of inflammatory bowel diseases," Biologics: Targets \& Therapy, vol. 3, pp. 77-97, 2009.

[28] S. Akira, K. Takeda, and T. Kaisho, "Toll-like receptors: critical proteins linking innate and acquired immunity," Nature Immunology, vol. 2, no. 8, pp. 675-680, 2001.

[29] X. Liu, Y. W. Ding, and H. Lin, "Expression of TLR2, TLR4, TLR5 and TLR9 in Hp infected mice," China Journal of Modern Medicine, vol. 22, no. 22, pp. 19-22, 2012.

[30] S. Sato, O. Takeuchi, T. Fujita, H. Tomizawa, K. Takeda, and S. Akira, "A variety of microbial components induce tolerance to lipopolysaccharide by differentially affecting MyD88-dependent and -independent pathways," International Immunology, vol. 14, no. 7, pp. 783-791, 2002.

[31] R. Jacinto, T. Hartung, C. McCall, and L. Li, "Lipopolysaccharide- and lipoteichoic acid-induced tolerance and crosstolerance: distinct alterations in IL-1 receptor-associated kinase," Journal of Immunology, vol. 168, no. 12, pp. 6136-6141, 2002.

[32] F. Schinzari, A. Armuzzi, B. de Pascalis et al., "Tumor necrosis factor- $\alpha$ antagonism improves endothelial dysfunction in patients with Crohn's disease," Clinical Pharmacology and Therapeutics, vol. 83, no. 1, pp. 70-76, 2008.

[33] A. Azuma, Y. J. Li, S. Abe et al., "Interferon- $\beta$ inhibits bleomycin-induced lung fibrosis by decreasing transforming growth factor- $\beta$ and thrombospondin," American Journal of Respiratory Cell and Molecular Biology, vol. 32, no. 2, pp. 93-98, 2005.

[34] M. H. G. Rep, R. Q. Hintzen, C. H. Polman, and R. A. W. van Lier, "Recombinant interferon- $\beta$ blocks proliferation but enhances interleukin-10 secretion by activated human T-cells," Journal of Neuroimmunology, vol. 67, no. 2, pp. 111-118, 1996.

[35] J. J. Kovarik, W. Tillinger, J. Hofer et al., "Impaired antiinflammatory efficacy of n-butyrate in patients with IBD,"
European Journal of Clinical Investigation, vol. 41, no. 3, pp. 291298, 2011.

[36] Z. Y. Tian, L. H. Wang, X. A. Su et al., "Study on dendritic cells and IL-6, IL-12 in the patients with ulcerative colitis," Chinese Journal of Gastroenterology and Hepatology, vol. 19, no. 11, pp. 1036-1038, 2010.

[37] N. C. Arbour, E. Lorenz, B. C. Schutte et al., "TLR4 mutations are associated with endotoxin hyporesponsiveness in humans," Nature Genetics, vol. 25, no. 2, pp. 187-191, 2000.

[38] K. R. Engelhardt and B. Grimbacher, "IL-10 in humans: lessons from the gut, IL-10/IL-10 receptor deficiencies, and IL-10 polymorphisms," in Interleukin-10 in Health and Disease, vol. 380 of Current Topics in Microbiology and Immunology, pp. 1-18, Springer, Berlin, Germany, 2014.

[39] L. Zou, L. Wang, X. Gong, H. Zhao, A. Jiang, and S. Zheng, "The association between three promoter polymorphisms of IL10 and inflammatory bowel diseases (IBD): a meta-analysis," Autoimmunity, vol. 47, no. 1, pp. 27-39, 2014.

[40] A. Shiotani, H. Kusunoki, Y. Kimura et al., "S100A expression and interleukin-10 polymorphisms are associated with ulcerative colitis and diarrhea predominant irritable bowel syndrome," Digestive Diseases and Sciences, vol. 58, no. 8, pp. 2314-2323, 2013.

[41] D. S. Shouval, A. Biswas, J. A. Goettel et al., "Interleukin-10 receptor signaling in innate immune cells regulates mucosal immune tolerance and anti-inflammatory macrophage function," Immunity, vol. 40, no. 5, pp. 706-719, 2014.

[42] G. Fonseca-Camarillo, J. Furuzawa-Carballeda, L. Llorente, and J. K. Yamamoto-Furusho, "IL-10- and IL-20-expressing epithelial and inflammatory cells are increased in patients with ulcerative colitis," Journal of Clinical Immunology, vol. 33, no. 3, pp. 640-648, 2013.

[43] P. J. Mannon, R. L. Hornung, Z. Yang et al., "Suppression of inflammation in ulcerative colitis by interferon- $\beta$-1a is accompanied by inhibition of IL-13 production," Gut, vol. 60, no. 4, pp. 449-455, 2011.

[44] E. Musch, T. Andus, M. Malek, A. Chrissafidou, and M. Schulz, "Successful treatment of steroid refractory active ulcerative colitis with natural interferon- $\beta$-an open long-term trial," Zeitschrift fur Gastroenterologie, vol. 45, no. 12, pp. 1235-1240, 2007.

[45] H. G. Wu, Z. Shi, Y. Zhu et al., "Clinical research for the herbpartition moxibustion treatment of ulcerative colitis," Shanghai Journal of Acupuncture and Moxibustion, vol. 26, no. 4, pp. 3-4, 2007.

[46] E.-H. Zhou, H.-R. Liu, H.-G. Wu et al., "Down-regulation of protein and mRNA expression of IL-8 and ICAM-1 in colon tissue of ulcerative colitis patients by partition-herb moxibustion," Digestive Diseases and Sciences, vol. 54, no. 10, pp. 2198-2206, 2009.

[47] X. M. Wang, Y. Lu, L. Y. Wu et al., "Moxibustion inhibits interleukin-12 and tumor necrosis factor alpha and modulates intestinal flora in rat with ulcerative colitis," World Journal of Gastroenterology, vol. 18, no. 46, pp. 6826-6835, 2012.

[48] H. G. Wu, H. R. Liu, L. Y. Tan et al., "Electroacupuncture and moxibustion promote neutrophil apoptosis and improve ulcerative colitis in rats," Digestive Diseases and Sciences, vol. 52, pp. 379-384, 2007. 


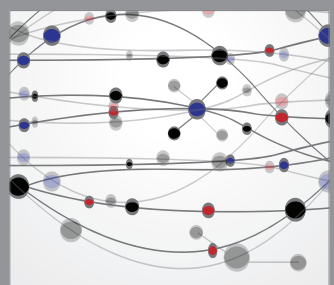

The Scientific World Journal
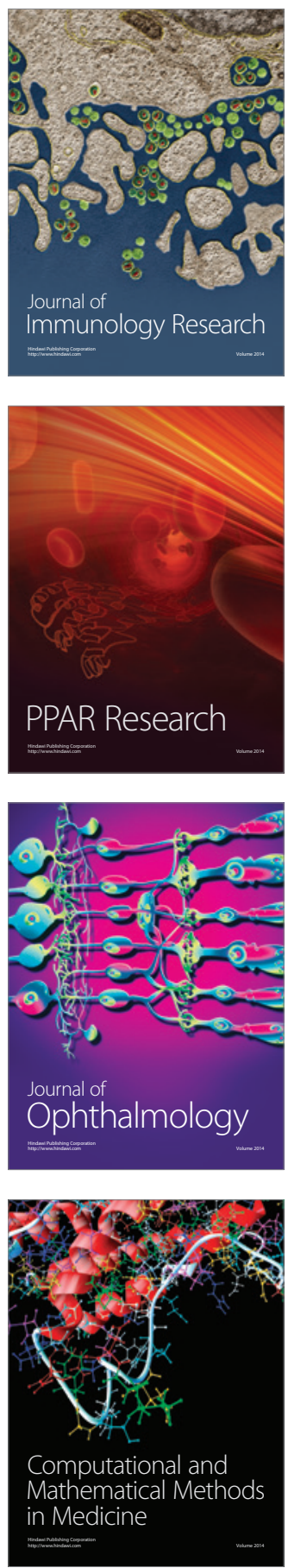

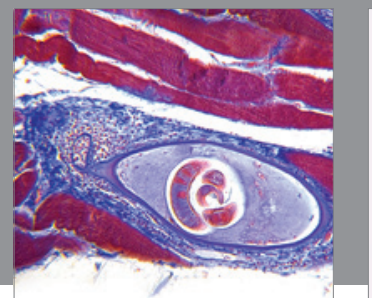

Gastroenterology

Research and Practice


\section{Hindawi}

Submit your manuscripts at

http://www.hindawi.com
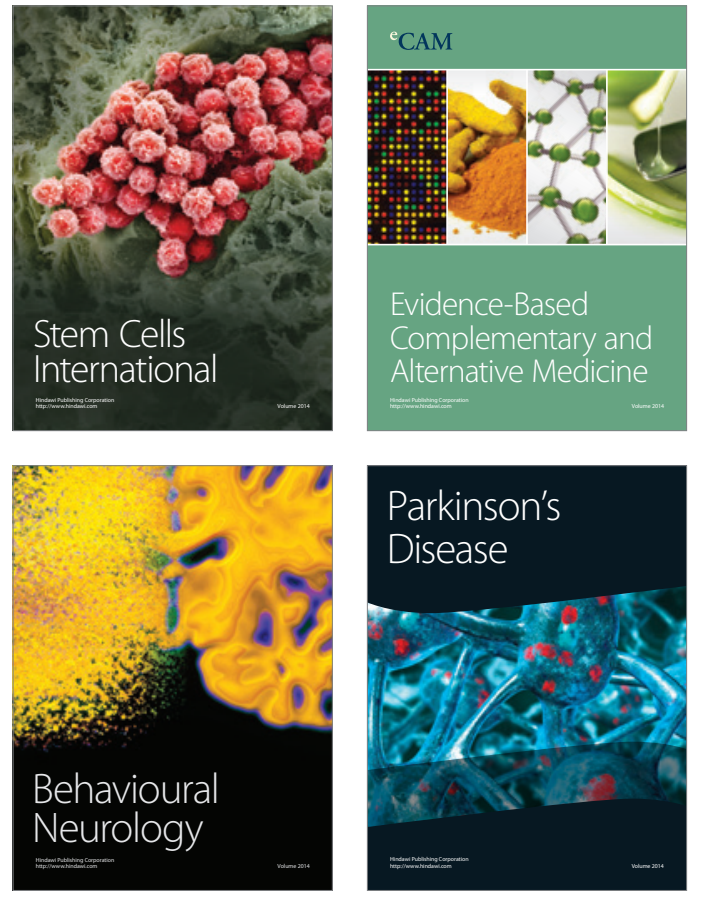
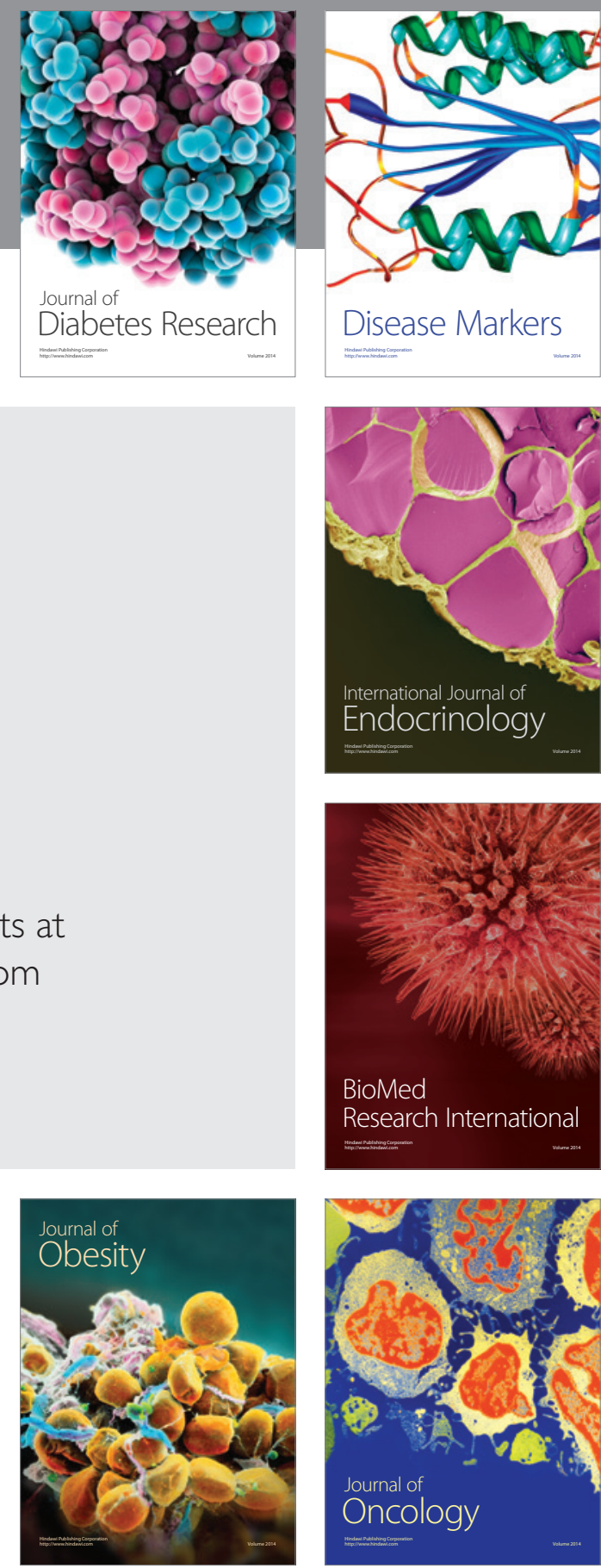

Disease Markers
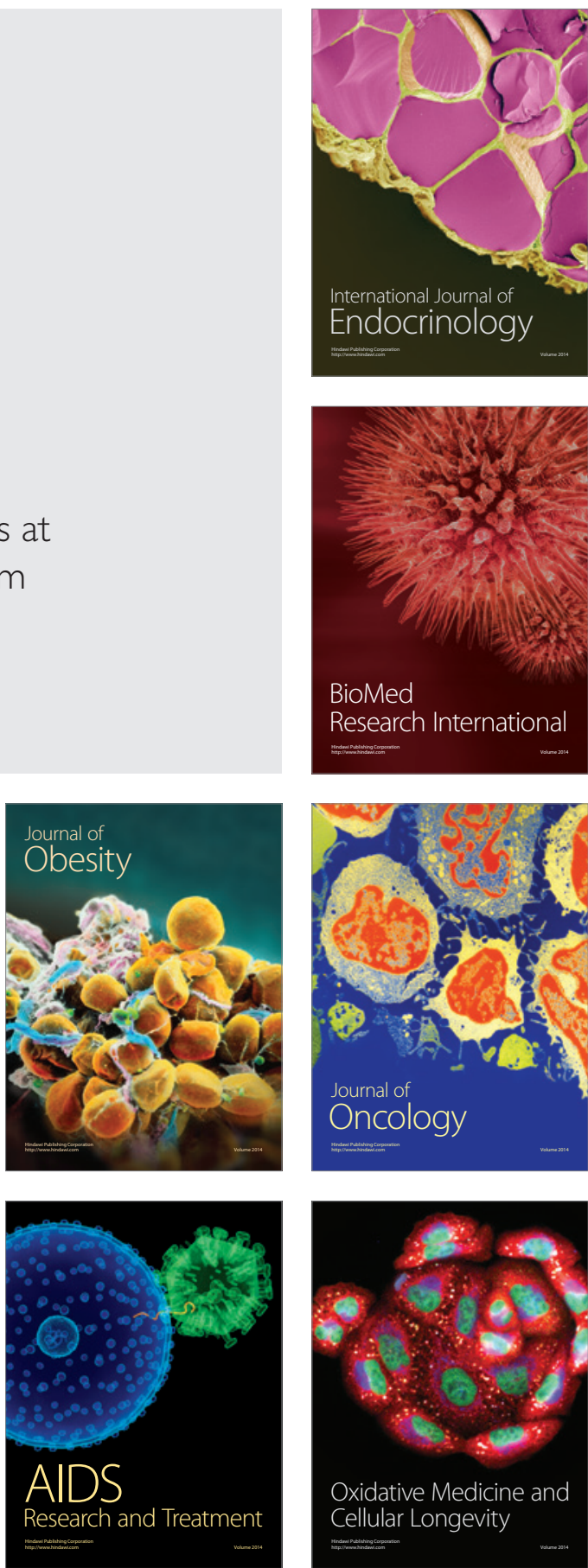